\title{
Assessment of Knowledge and Compliance with Covid-19 Safety Precautions and Protocols In Federal Medical Centre Bida, Niger State-Nigeria
}

\author{
Ajayi Abraham Dare, Gaknung Bonji Kopdimma, Gotodok Kopdima Hosea, Shaba Victoria \\ Ladi, Okpe Cletus $O$
}

\begin{abstract}
BACKGROUND; COVID 19 is a new disease, and many of the details of its spread are still under investigation. It spreads easily between people more easily than influenza but not as easily as measles, although it can be prevented with strict adherence to safety precautions and protocols especially in hospital settings.

AIM OF THE STUDY:

The main aim of this study is to assess the level of knowledge of COVID-19, ascertain the available safety precautions and protocols as well as its compliance rate among staff of FMC Bida Niger State - Nigeria.

METHODS:

Descriptive survey design particularly cross-sectional survey design was used in the study. The population of study comprises of all staff of Federal Medical Centre Bida, Niger State whose total population is One Thousand Six Hundred and Eighty Three $(1,683)$ as at the time of data collection. There are 1,683 staff in federal medical center Bida, out of which 323 respondents were drawn to participate in the study by using multi-stage sampling technique and Yamane's (2000) sample size formula. Semi-structured questionnaire was used for data collection. The questionnaire was organized into sections A-D. Data was analyzed using Statistical Package for Social Science (SPSS) version 22 and presented using frequency distribution tables and expressed as percentages.
\end{abstract}

\section{RESULT:}

The result of this study revealed that significant large number of staff $219(85.2 \%)$ have good knowledge of COVID-19, while $36(14.0 \%)$ and $2(0.8 \%)$ have fair and poor knowledge respectively. In term of available COVID-19 safety precautions and protocol put in place by the management of FMC Bida, the results revealed that majority of the staff 180 $\mathbf{7 0 . 0 \% )}$ strongly agreed that there are preventive protocols such as hand washing points, isolation rooms for suspected cases, compulsory wearing of face mask and social distancing protocols in the hospital except PPEs which are under supply to the staff. The results on compliance rate of staff to the available COVID-19 safety precautions and protocols revealed that about half of the respondents $120(46.7 \%)$ do not comply with the outline protocols by the hospital management. CONCLUSION:

The study concludes that good knowledge of COVID-19 with availability and compliance to safety precautions and protocols

\footnotetext{
Ajayi Abraham Dare, Department of Nursing Sciences, Faculty of Health Science and Technology, University of Jos.

Gaknung Bonji Kopdimma, Department of Nursing Sciences, Faculty of Health Science and Technology, University of Jos.

Gotodok Kopdima Hosea, Department of Nursing Sciences, Faculty of Health Science and Technology, University of Jos.

Shaba Victoria Ladi, Department of nursing sciences, National Open University Nigeria (NOUN) Abuja.

Okpe Cletus O, Department of Nursing Sciences, Faculty of Health Science and Technology, University of Jos.
}

as directed by the Nigerian Centre for Disease Control is key to the prevention and spread of COVID-19 in the hospital settings. It was recommended that there is high need for all staff especially those in clinical departments to comply with the available safety precautions and protocols of COVID-19 in the hospital and beyond to minimize spread of the disease and the hospital management should provide adequate PPEs to both clinical non-clinical staff.

Index Terms - COVID-19, Compliance, Knowledge, and Safety Precaution and Protocols.

\section{INTRODUCTION}

Corona viruses are a large family of RNA viruses that infect birds and many mammals including humans. These viruses cause illnesses that range from common cold to more severe respiratory diseases and rarely gastroenteritis. Corona virus disease (COVID-19) is caused by an emerging strain of corona virus (SARS-Cov-2) that has not been previously identified in humans, belonging to the same family of viruses responsible for severe acute respiratory syndrome (SARS) and Middle East respiratory syndrome (MERS), for which zoonotic and person- to-person transmission have been confirmed (Nigerian Centre for Disease Control, 2020).

The COVID-19 pandemic, also known as the corona virus pandemic, is an on-going global pandemic of corona virus disease 2019 (COVID-19), caused by severe acute respiratory syndrome corona virus 2 (SARS-CoV-2) (World Health Organization, 2020). The outbreak was first identified in December 2019 in Wuhan, China (Huang,Wang, Li, Ren, Zhao, \& Hu, 2020). The World Health Organization declared the outbreak a Public Health Emergency of International Concern on 30 January 2020 and a pandemic on 11 March.

Common symptoms include fever, cough, fatigue, shortness of breath and loss of sense of smell. Complications may include pneumonia and acute respiratory distress syndrome. The time from exposure to onset of symptoms is typically around five days but may range from two to fourteen days. There are several vaccine candidates in development, although none have completed clinical trials to prove their safety and efficacy. There is no known specific antiviral medication, so primary treatment is currently symptomatic (Velavan, \& Meyer; U.S CDC, 2020)

Recommended preventive measures include hand washing, covering one's mouth when coughing, maintaining distance from other people, wearing a face mask in public settings, disinfecting surfaces, increasing ventilation and air filtration indoors, and monitoring and self-isolation for people who 
suspect they are infected (National Center for Immunization and Respiratory Diseases NCIRD, 2020). Authorities worldwide have responded by implementing travel restriction, lockdowns, workplace hazard controls, and facility closures in order to slow the spread of the disease. Many places have also worked to increase testing capacity and trace contacts of infected persons.

According to NCDC (2020), key infection prevention and control (IPC) strategies to limit or prevent transmission in healthcare settings include the following: Ensuring triage, early recognition, and source control (isolating) of patients with suspected SARS-CoV-2 (COVID-19) infections, application of standard precautions for all patients at all times, implementation of empiric additional precautions droplet and contact precautions in the care of suspected and

confirmed cases of COVID-19 and airborne precautions (in certain situations when aerosol generating procedures are carried out on COVID-19 patients), implement administrative controls and use of environmental and engineering controls such as adequate spatial separation of patients, appropriate ventilation and appropriate cleaning of the environment.

Elements of Standard Precautions which are important in the care of patients with respiratory infections, including those caused by COVID-19, are: respiratory hygiene and cough etiquette, appropriate use of PPE (based on risk assessment) e.g. Gloves, Facial protection (eyes, nose and mouth), gowns and aprons, as well as patient placement with adequate ventilation.

\section{Statement of the Research Problem}

Since the outbreak of COVID -19 pandemic in December 2019 in Wuhan China, more than 22.4 million cases have been reported in more than 188 countries and territories, resulting in more than 787,000 deaths and more than 14.3 million recoveries as at $20^{\text {th }}$ August 2020 (Center for Systems Science and Engineering CSSE, 2020). The World Health Organization (2020), declared the outbreak a Public Health Emergency of International Concern on 30 January 2020 and a pandemic on 11 March.

The pandemic has caused global social and economic disruption, including the largest global recession since the Great Depression (International Monetary Fund IMF, 2020). Up to 100 million people have fallen into extreme poverty and global famines are affecting 265 million people (World Bank; United Nation, 2020). It has led to the postponement or cancellation of sporting, religious, political, and cultural events, widespread supply shortages exacerbated by panic buying, and decreased emissions of pollutants and greenhouse gases (Scipioni; Watts, \& Kommenda,2020). Schools, universities, and colleges have been closed either on a nationwide or local basis in 161 countries, affecting approximately 98.6 percent of the world's student population (UNESCO, 2020). Misinformation about the virus has circulated through social media and mass media. There have been incidents of xenophobia and discrimination against Chinese people and against those perceived as being Chinese or as being from areas with high infection rates (Clamp; Lee, \& Yadav, 2020).

Following the first case of COVID 19 in Africa in early
February 2020, the continent has recorded $1,168,185$ cases, 27,322 deaths and 889,388 recoveries as at $21^{\text {st }}$ August 2020 with Nigeria third most affected country after South Africa and Egypt (Africa Centre for Disease Control, 2020). As at $21^{\text {st }}$ August 2020, Nigeria has recorded 51,304Confirmed Cases with 12,423 Active Cases, 37,885 Discharged and 996Deaths.

Niger state is one of the affected states in Nigeria and has recorded 232 confirmed cases with 52 still on admission (active cases), 168 discharges and 12 deaths of COVID-19 pandemic. Federal Medical Centre (FMC) Bida as the only tertiary health institution in the state has recorded suspected and confirmed cases of COVID-19 amongst its staff and patients since the state recorded its first case in April 2020. This has led to increased concern about staff and patients safety by the Hospital management and it's therefore, imperative to assess the level of knowledge of COVID-19, ascertain the available safety precautions and protocols as well as its compliance rate among staff of FMC Bida Niger State - Nigeria, as there are currently little or no researches on this preventive aspect of the disease.

\section{Significance of the Study}

COVID-19 is a new disease, and many of the details of its spread are still under investigation. It spreads easily between people more easily than influenza but not as easily as measles (U.S CDC, 2020). Therefore, in Hospitals where exposure to COVID-19 may occur, good knowledge of the disease transmission and adequate compliance to safety precautions and protocols is a critical first step in protecting staff, patients and visitors. The result obtained from this study will be communicated to the Hospital management, staff and other health institutions at large.

This will create more awareness to the staff on the need to take more precautions about the disease and motivate the Hospital management to improve on the deficient areas of preventive measures and protocols to further improve staff safety and working environment.

\section{Objectives of the Study}

To assess the level of knowledge and compliance of staff on COVID-19 in Federal Medical Centre Bida, Niger state.

Global and National Perspective of Covid-19 Pandemic The WHO has not yet declared a pandemic ofSARS-CoV-2, the virus that causes COVID-19. The epidemic began in December 2019 (Xu, Chen, Wang, Feng, Zhou \& Li, 2020). Extraordinary and unprecedented measures taken in China, which involved travel restrictions for almost half the population and lockdown of a population greater in size than the entire population of the United States, has resulted in a decline in cases in China. However, as the epidemic came under control in

China, outbreaks on a cruise ship docked Japan, in the Republic of Korea, Italy and Iran have raised concerns about a pandemic being imminent. Whilst there are several different definitions of a pandemic, we are waiting to see evidence of sustained domestic transmission in two or more continents The virus has pandemic potential as it is a respiratory virus, which is comparable to influenza ( $\mathrm{Li}$, Guan, Wu, Wang, Zhou, \& Tong 2020; Peak, Childs, Grad, Buckee, 
2017).Outbreaks have also occurred in closed settings such as prisons, hospitals and aged care facilities, with growing localized epidemics in other countries. In Iran, a high ratio of deaths to cases suggests a substantial proportion of undiagnosed cases and Community transmission.

The most important difference in transmission of COVID-19 compared to SARS in 2003 is that substantial transmission is possible with mild symptoms or no symptoms.

\section{METHODOLOGY}

\section{Study Area}

Bida is a Local Government Area located in the southwest of Niger state, Nigeria. The LGA has an area of $51 \mathrm{~km}^{2}$ and a population of 188,181 at the 2006 census. Bida is the traditional headquarters of Nupe Kingdom. The Nupes live in the low basin formed by the two valleys of Rivers Niger and Kaduna. They are basically civil servants and business men/women and predominantly Muslims. The ancient town of Bida is one of the twelve towns founded by the Bin is around the fourteenth century. The town is said to have been a base for hunters, therefore, it was safe from marauders. The Federal Medical Centre, Bida (FMCBida) is a federal medical centre own by the federal government of Nigeria and built by the Sani Abacha military administration in 1997. It is the only tertiary healthcare institution in Niger state with 26 departments and located at south-west of Bida along Niger State College of Nursing road.

\section{Study Design}

A descriptive cross-sectional survey design was used to describe the level of knowledge of staff on COVID-19, identify safety precautions and protocols in the hospital as well as resultant compliance level by the staff.

\section{Study Population}

The population of study comprises of all staff of Federal Medical Centre Bida, Niger State whose total population is One Thousand Six Hundred and Eighty Three $(1,683)$ as at the time of data collection.

\section{Sample Size and Sampling Technique}

A multi-stage sampling technique was used to select the staff from all the twenty six (26) departments in the Hospital which include (Nursing Services, Surgery, Accident and Emergency, ENT, Anaesthesia, Family Medicine, Radiology, Dental Surgery, Paediatrics, Ophthalmology, Internal Medicine, Community Medicine, O \& G, Mental Health, Administration, Finance, Internal Audit, Works and Estate, Haematology, Medical Microbiology, Chemical Pathology, Anatomy/Histopathology, Pharmacy, Physiotherapy, Health Records, Medical Social Welfare and Phlebotomy) to participate in the study. A total of 1,683 was the target population, out of which 323 respondents (sample size) were drawn to participate in the study by using Yamane's (2000) sample size formula as calculated below.

\section{Instrument of data collection}

The instrument for collecting the data was a semi-structured questionnaire. The content of the questionnaire was guided by review of literature on global and national perspectives of COVID-19 and recommended safety precautions and protocols by international health organization and NCDC. The questionnaire was organized into four sections. Section A elicited information on demographic attributes of respondents. Section B elicited information on COVID-19 knowledge, Section C elicited questions related to safety precaution measures and protocols put in place by the Hospital management on COVID-19 and the response format was in line with the modified likert scale of summative rating with four point scale of strongly agree, agree, disagree and strongly disagree for question one and other questions followed a 2 way dichotomous format of yes or no. Section D also had seven questions to elicit information on compliance level of the staff towards the instituted safety precaution measures and protocols.

\section{Validity and Reliability of instrument}

A pilot test was carried out at the General Hospital Bida, among 20 staff. The instrument was administered to them and the reliability showed Cronbatch alpha of 0.7.This result showed that the instrument was reliable with $70 \%$ hence; it could be used to elicit the desirable responses.

\section{Method of Data Collection}

The researcher produced 323 copies of questionnaire which were directly administered by the researcher and three other research assistants. All respondents could read and write; therefore questionnaires were given to them to respond without any difficulty.

\section{Method of Data Analysis}

The data was sorted out after collection of the questionnaires from the respondents. Data was analyzed using Statistical Package for Social Science (SPSS) version 22 and presented using frequency distribution tables and expressed as percentages. For the purpose of this study, a scoring system was used to grade level of knowledge of the respondents on COVID-19 pandemic into good, fair and poor knowledge. Ten questions were asked and each carries one mark. A score of 7-10 marks was considered as good knowledge, 5-6 fair knowledge and 0-4 poor knowledge.

\section{Ethical Consideration}

Ethical clearance was obtained from Federal Medical Centre Bida ethical clearance committee for the research permit. The purpose of the study was explained to the participants. Informed consent was sought from all those involve in the study before administering the questionnaire. Confidentiality of respondents was strictly ensured while participation in the study was voluntary and the participants were free to withdraw from the study at any time without incurring any penalties. Anonymity was assured by using rank and ward/unit for identification instead of names. 
III. RESULTS

Table 1 Distribution of Respondents according to their Socio-demographic data. Total $(\mathrm{N})=\mathbf{2 5 7}$

\begin{tabular}{|c|c|c|}
\hline Variables & Frequency & Percentage \\
\hline \multicolumn{3}{|l|}{ Age } \\
\hline $20-30$ & 79 & 30.7 \\
\hline $31-40$ & 122 & 47.5 \\
\hline $41-50$ & 46 & 17.9 \\
\hline $51-60$ & 10 & 3.9 \\
\hline \multicolumn{3}{|l|}{ Gender } \\
\hline Female & 132 & 51.4 \\
\hline Male & 125 & 48.6 \\
\hline \multicolumn{3}{|l|}{ Cadre } \\
\hline Junior & 82 & 31.9 \\
\hline Senior & 175 & 68.1 \\
\hline \multicolumn{3}{|l|}{ Profession } \\
\hline Nursing & 91 & 35.4 \\
\hline Medicine & 41 & 16 \\
\hline Pharmacy & 7 & 2.7 \\
\hline MLS & 7 & 2.7 \\
\hline Physiotherapy & 3 & 1.2 \\
\hline Radiology & 19 & 7.4 \\
\hline Medical Record & 40 & 15.6 \\
\hline Others & 49 & 19.1 \\
\hline \multicolumn{3}{|c|}{ Year of Experience } \\
\hline $0-5$ & 89 & 34.6 \\
\hline $6-10$ & 67 & 26.1 \\
\hline $11-15$ & 67 & 26.1 \\
\hline $16-20$ & 10 & 3.9 \\
\hline $21-25$ & 10 & 3.9 \\
\hline $26-30$ & 7 & 2.7 \\
\hline $31-35$ & 7 & 2.7 \\
\hline
\end{tabular}

Table 1 above showed that majority of respondents 122(47.5) are within the age range of 31-40 years followed by 20-30 years $79(30.7 \%)$ and the least age range who participated in the study was 51-60 years $10(3.9 \%)$. The table also revealed that majority of the staff $132(51.4 \%)$ who participated in the study were females while male participants constitute 125 (48.6\%). In term of cadre, majority of the respondents $175(68.1 \%)$ were senior staff and a good number of these senior staff 91 (35.4\%) were in Nursing services department, medicine 41 (16\%), medical record $40(19.1 \%)$ and others from departments such as administration, audit, finance, works and estate of the hospital. Finally, the table also revealed that majority of the respondents $89(34.6 \%)$ had

0-5 years of working experience, followed by 6-10 and 11-15years 67 (26.1\%) while the least participants were staff with 31-35 years 7 (2.7\%) of working experience. 
Table 2 Showing Respondents' Knowledge on COVID-19 Pandemic (N=257)

COVID-19 is an infectious disease caused by?

Bacteria

Viruses

Fungi

Algae

COVID-19 was first discovered in?

Nigeria

USA

South Korea

China

The followings are signs and symptoms of COVID-19 except?

Fever

Shortness of breath

Cough

Loss of Smell

Excessive sleeping

What would you do if you experience the above symptoms?
(a)Stay at home only

(b)Stay at home and dial NCDC Toll-Free number

(c)Visit nearby health centre and inform the health personnel about the symptoms

(b) and (c) above

COVID-19 can be transmitted from person-to-person through?

Respiratory droplets

Touching contaminated surfaces

Hand shaking

Travelling to high risk places

All of the above

COVID-19 can be prevented through?

$\begin{array}{ll}\text { Regular hand washing with soap and water } & 6\end{array}$

Avoid crowded places

Wearing of face mask

Maintain social distance

Early detection and isolation of suspected persons

All of the above

Nigeria recorded first COVID-19 confirmed case in?

Jan-20

3.9

Feb-20

Mar-20

COVID-19 is a public health emergency of international concern;

Infected people with COVID-19 can recover completely;

YES

COVID-19 pandemic has caused global social and economic disruption; 
Result of data analysis on the staff's knowledge on COVID-19 in table 2 revealed that more than two-third of the staff displayed good knowledge on the variables tested. Majority of the respondents $220(85.6 \%)$ said COVID-19 is an infectious disease caused by a virus, 30 (11.7\%) said bacteria while only $2(0.8 \%)$ said algae. Almost all respondents $250(97.2 \%)$ believe that COVID-19 was first discovered in China while only 7 (2.8\%) said South Korea. In an attempt to elicit the staff's knowledge on signs and symptoms of COVID-19, majority 240 (93.4\%) responded that fever, shortness of breath, cough and loss of smell are all signs and symptoms of COVID-19 while only 11 (4.3\%) selected fever as the only signs and symptoms of COVID-19. Furthermore, majority of the respondents 222 (86.4\%) opined that they will stay at home and dial NCDC Toll-Free number whenever they experience above listed COVID-19 signs and symptoms while $15(5.8 \%)$ opined that they will visit any nearby health centre and inform the health personnel. In term of transmission of the viral disease, majority of the staff 228 $(88.7 \%)$ believe that the virus can be transmitted through respiratory droplets, touching of contaminated surfaces, hand shaking and travelling to high risk places while $10(3.9 \%)$ only believe that the virus is transmitted only by travelling to high risk places. In the same vein, large number of the respondents $203(78.9 \%)$ also believe that regular hand washing with soap and water, avoidance of crowded places, wearing of face mask, maintaining social distance and early detection and isolation of suspected persons are all preventive measures of COVID-19 while $15(5.8 \%)$ believe that wearing of face mask and maintaining social distance is sufficient to prevent the disease. In term of historic perspective of the disease in Nigeria, majority of the respondents 198 (77.0\%) said that Nigeria recorded her first case in February 2020 while $38(14.8 \%)$ said March 2020 and only 10 (3.9\%) said January 2020 . The table also revealed that the majority of the respondents

$246(95.7 \%)$ confirmed that COVID-19 is a public health emergency of international concern although few respondents $11(4.3 \%)$ said it's not. As regards recovery from the disease when infected, a good number of the respondents 184 (71.6\%) opined that infected people can recover completely from COVID-19 while $73(28.4 \%)$ had opposite view. Finally, majority of the respondents $(234(91.1 \%)$ believe that the pandemic has caused global and economic disruption while only $23(8.9 \%)$ do not believe.

Table 3 Showing Scores of Respondents' Level of Knowledge on COVID-19

\begin{tabular}{|lll|}
\hline Variables & Frequency & Percentage\% \\
Good & 219 & 85.2 \\
Fair & 36 & 14.0 \\
Poor & 2 & 0.8 \\
Total & 257 & 100 \\
& & \\
\hline
\end{tabular}

Table 3 above contains the summary of staff's level of have fair and poor knowledge respectively.

knowledge on COVID-19 pandemic. The result revealed that significant large number of staff $219(85.2 \%)$ have good

Table 4 Showing Available COVID-19 Safety Precaution and Protocols in FMC BIDA (N=257)

\begin{tabular}{|c|c|c|}
\hline Variables & Frequency & Percentage $(\%)$ \\
\hline \multicolumn{3}{|c|}{ There is hand washing point (s) and sanitizer (s) at the entrance of all the buildings in the Hospital. } \\
\hline Strongly Disagree & 22 & 8.6 \\
\hline Disagree & 34 & 13.2 \\
\hline Undecided & 9 & 3.5 \\
\hline Agree & 97 & 37.7 \\
\hline Strongly Agree & 95 & 37 \\
\hline \multicolumn{3}{|c|}{ All healthcare personnel are provided with adequate PPEs. } \\
\hline Strongly Disagree & 118 & 45.9 \\
\hline Disagree & 72 & 28 \\
\hline Undecided & 10 & 3.9 \\
\hline Agree & 26 & 10.1 \\
\hline Strongly Agree & 31 & 12.1 \\
\hline \multicolumn{3}{|c|}{ There is a designated isolation room (s) for keeping suspected case (s) before COVID-19 test is carried out. } \\
\hline Strongly Disagree & 9 & 3.5 \\
\hline Disagree & 24 & 9.3 \\
\hline Undecided & 34 & 13.2 \\
\hline Agree & 77 & 30 \\
\hline Strongly Agree & 113 & 44 \\
\hline \multicolumn{3}{|c|}{ There are public enlightenment posters on COVID-19 awareness creation across the Hospital environment. } \\
\hline Strongly Disagree & 5 & 1.9 \\
\hline
\end{tabular}




\begin{tabular}{|lll}
\hline Disagree & 26 & 10.1 \\
Undecided & 19 & 7.4 \\
Agree & 125 & 48.6 \\
Strongly Agree & 82 & 31.9 \\
All staff are trained on COVID-19 safety precautions and use of PPEs & \\
Strongly Disagree & 41 & 16 \\
Disagree & 82 & 31.9 \\
Undecided & 38 & 14.8 \\
Agree & 62 & 24.1 \\
Strongly Agree & 34 & 13.2 \\
The Hospital management has cancelled visiting hours by visitors and patients' relatives. & \\
Strongly Disagree & 41 & 16 \\
Disagree & 77 & 30 \\
Undecided & 24 & 9.3 \\
Agree & 72 & 28 \\
Strongly & 43 & 16.7 \\
Agree & & \\
The Hospital management has reduced number of staff in all offices to ensure social distancing protocol. & \\
Strongly Disagree & 22 & 8.6 \\
Disagree & 43 & 16.7 \\
Undecided & 31 & 12.1 \\
Agree & 91 & 35.4 \\
Strongly Agree & 70 & 27.2 \\
The Hospital management has enforced compulsory use of face mask by staff and patients \\
Strongly Disagree & 7 & \\
Disagree & 36 & 2.7 \\
Undecided & 19 & 14 \\
Agree & 108 & 7.4 \\
Strongly Agree & 87 & 42 \\
& & 33.9 \\
\hline
\end{tabular}

Table 4 above revealed that majority of the 97 (37.7\%) agreed that there is a hand washing point and sanitizer at the entrance of all the buildings in the hospital while an equally good number 95 (37.0\%) strongly agreed and $9(3.5 \%)$ were undecided. In term of PPEs availability, majority of the respondents 118 (45.9\%) strongly disagreed that all healthcare personnel in the hospital are provided with adequate PPEs, $72(28.0 \%)$ of the staff also disagree while only $31(12.1 \%)$ strongly agreed that PPEs are provided. The table also showed that a good number of the respondents strongly agreed that there is a designated isolation room (s) for managing suspected cases of COVID-19 before confirmatory test is conducted. Furthermore, it's also gathered from that table that majority of the staff $125(48.6 \%)$ agreed that there are posters on COVID-19 awareness creation across the hospital environment, 26 (10.1\%) disagreed while $19(7.4 \%)$ were undecided. In term of training on COVID-19, a good number of the respondents 82 (31.9\%) disagreed that all staff are trained on COVID-19 safety precautions and use of PPEs while $62(24.1 \%)$ agreed and $38(14.8 \%)$ were undecided. In an attempt to investigate social distancing protocol, majority of the respondents 77 (30.0\%) disagreed that the hospital management has cancelled visiting hours by visitors and patients' relatives, 72 $(28.0 \%)$ agreed while $24(9.3 \%)$ were undecided. In the same vein, majority of the respondents $91(35.4 \%)$ agreed that the hospital management has reduced number of staff in all offices to ensure social distancing protocol, $70(27.2 \%)$ also strongly agreed and only $43(16.7 \%)$ disagreed. Finally, the table also revealed that majority of the respondents 108 $(42 \%)$ agreed that the hospital management has enforced compulsory use of face mask by staff and patients, 87 (33.9\%) also strongly agreed while $36(14.0 \%)$ disagreed.

Table 5 Showing Compliance of Staff to COVID-19 Safety Precautions and Protocols.

\begin{tabular}{|lcc|}
\hline Variables & Frequency & Percentage (\%) \\
Do you wash your hands before entrance to all buildings and contact with patients? \\
No & 48 & 18.7 \\
Yes & 209 & 81.3 \\
Total & 257 & 100 \\
When do you use PPEs? & & 44 \\
Before going to patient & 113 & \\
ward & & \\
\hline
\end{tabular}




\begin{tabular}{|c|c|c|}
\hline $\begin{array}{l}\text { Inside the ward before } \\
\text { contact with patients }\end{array}$ & 41 & 16 \\
\hline I don't use PPE & 103 & 40 \\
\hline Total & 257 & 100 \\
\hline \multicolumn{3}{|c|}{ Do you sanitize your hand while at work? } \\
\hline No & 12 & 4.7 \\
\hline Yes & 245 & 95.3 \\
\hline $\begin{array}{l}\text { If Yes, how often? } \\
\text { After contact with } \\
\text { contaminated surfaces }\end{array}$ & 38 & 15.5 \\
\hline After contact with patients & 26 & 10.6 \\
\hline Any time I see sanitizer & 39 & 15.9 \\
\hline All of the above & 142 & 58.0 \\
\hline Total & 245 & 100 \\
\hline \multicolumn{3}{|c|}{ Do you wear face mask at work? } \\
\hline No & 17 & 6.6 \\
\hline Yes & 240 & 93.4 \\
\hline Total & 257 & 100 \\
\hline \multicolumn{3}{|l|}{ If Yes, how often? } \\
\hline When attending to patients & 29 & 12.1 \\
\hline $\begin{array}{l}\text { When talking to patient and } \\
\text { colleagues }\end{array}$ & 9 & 3.75 \\
\hline $\begin{array}{l}\text { When going to any building } \\
\text { / office }\end{array}$ & 22 & 9.2 \\
\hline All of the above & 180 & 75 \\
\hline Total & 240 & 100 \\
\hline
\end{tabular}

Since the outbreak of COVID-19, have you been instructed by the management to work from home before?

$\begin{array}{lll}\text { No } & 204 & 79.4 \\ \text { Yes } & 53 & 20.6 \\ \text { Total } & 257 & 100\end{array}$

If YES, for how many weeks?

$\begin{array}{lll}1-2 \text { weeks } & 24 & 45.3 \\ \text { 3-4 weeks } & 12 & 22.6 \\ 5-7 \text { weeks } & 10 & 18.7 \\ \text { Above } 8 \text { weeks } & 7 & 13.2 \\ \text { Total } & 53 & 100\end{array}$

Table 5 above revealed that majority of the respondents $209(81.3 \%)$ confirmed that they wash their hands before going into all buildings and contact with patients while only $48(18.7 \%)$. In term of PPEs usage, majority of the staff 113 (44.0\%) said they usually use PPEs before going to patients' ward, $41(16.0 \%)$ said inside the ward before contact with patients while a good number $103(40.0 \%)$ said they do not use PPEs. In the same vein, majority of the respondents 245 (95.3\%) affirmed that they usually sanitize their hands at work while $12(4.7 \%)$ said they do not and among the 245 (95.3\%) who usually sanitize their hands, majority said it's usually after contact with contaminated surfaces and patients and any time they see hand sanitizer while only $38(15.5 \%)$ said its only after contact with contaminated surfaces. The table further showed that majority of the respondents 240
(93.4\%) confirmed that they wear face mask when at work while only $17(6.6 \%)$ said they do not and among the 240 (93.4\%) respondents who wear face mask, majority 180 $(75.0 \%)$ said it's often when they are attending to patients, talking to patients and colleagues and when going to any building/office while $29(12.1 \%)$ said only when they are attending to patients. The table also revealed that majority of the respondents $204(79.4 \%)$ said the hospital management has not instructed them to work from home since the out of the pandemic while few respondents $53(20.6 \%)$ said they have work from home before as instructed by the hospital management. Majority of respondents 24 (45.3\%) who have worked from said its was for 1-2 weeks while only 7 (13.2\%) was for above 8 weeks. 


\section{DISCUSSION OF FINDINGS}

The general aim of this study is to assess the level of knowledge of COVID-19, ascertain the available safety precautions and protocols as well as its compliance rate among staff of FMC Bida Niger State - Nigeria. The findings showed that frontline health care workers had an 11.6-times higher risk of testing positive than community individuals. Hence, the needs for hospital staff especially the healthcare workers to have good knowledge of the pandemic.

The results on compliance rate of staff to the available COVID-19 safety precautions and protocols revealed that majority of the respondents $209(81.3 \%)$ confirmed that they wash their hands before going into all buildings and contact with patients while only $48(18.7 \%)$. Scientifically, it's proven that 20 seconds of hand washing with plain soap and water are powerful enough to destroy microscopic corona virus particles and help prevent the spread of the disease. Hand washing is more effective than hand sanitizing only, therefore hands can further be sanitized after thorough washing with soap and water. In term of PPEs usage, majority of the staff $113(44.0 \%)$ said they usually use PPEs before going to patients' ward, $41(16.0 \%)$ said inside the ward before contact with patients while a good number 103 $(40.0 \%)$ said they do not use PPEs. PPEs are better wore before contact with patients and disposed immediately in a safe waste bin thereafter for further incineration.

\section{CONCLUSION AND RECOMMENDATIONS.}

From the results of the study, it can be concluded that staff of Federal Medical Centre Bida have a significant good knowledge of COVID-19 safety precautions and protocols but the compliance to these the protocols is suboptimal. The availability of some vital protocols such as adequate provision of PPEs and clinical trainings is also not sufficient. It can therefore be concluded that good knowledge of COVID-19 with availability and compliance to safety precautions and protocols as directed by the Nigerian Centre for Disease Control is key to the prevention and spread of COVID-19 in the hospital settings.

\section{Recommendations}

The following recommendations were made based on the objectives of the study.

1. There is high need for all staff especially those in clinical departments to comply with the available safety precautions and protocols of COVID-19 in the hospital and beyond to minimize spread of the disease.

2. The hospital management should provide adequate PPEs to both clinical non-clinical staff.

3. The hospital management should also ensure that all staff are adequately trained on the use of PPEs and other safety precautionary measure of COVID-19.

\section{REFERENCES}

[1]Bai, Y.Y., Lingsheng,W., Tao, T., Fei, J., Dong, Y., Chen,L., \& Wang, M. (2020). Presumed Asymptomatic Carrier Transmission of COVID-19. JAMA. 2020; Published online February 21, 2020 doi:10.1001/jama.2020.2565.
[2]Bourouiba, L. (2020).Turbulent Gas Clouds and Respiratory Pathogen Emissions: Potential Implications for Reducing Transmission of COVID-19. JAMA. doi:10.1001/jama.2020.4756. PMID 32215590.

[3]Chan, J.F.W., Yuan, S., Kok, K.H., To, K.K.W., Chu, H., \&Yang, J. (2020). A familial cluster of pneumonia associated with the 2019 novel corona virus indicating person-to-person transmission: a study of a family cluster. The Lancet. 2020.

[4] Clamp, R. (2020).Corona virus. The Conversation. Retrieved 14 March 2020.

[5]European Centre for Disease Prevention and Control(2020).Checklist for hospitals preparing for the reception and care of corona virus 2019 (COVID-19) patients (Report). 26 February 2020. Retrieved 27 March 2020.

[6]Huang, C., Wang, Y., Li, X., Ren, L., Zhao, J., \&Hu, Y. (2020).Clinical features of patients infected with 2019 novel corona virus in Wuhan, China". Lancet. 395 0223):497 506. doi:10.1016/s0140-6736(20)30183-5. PMC 7159299. PMID 31986264

[7] Johns Hopkins University (2020). COVID-19 Dashboard by the Center for Systems Science and Engineering (CSSE) at Johns Hopkins University (JHU). ArcGIS. Johns Hopkins University. Retrieved 19 August 2020.

[8]Lee, J., Yadav, M. (2020).The Rise of Anti-Asian Hate in the Wake of Covid-19. Social Science Research Council. Social Science Research Council. Retrieved 3 July 2020.

[9]Li, Q., Guan, X., Wu, P., Wang, X., Zhou, L., \&Tong, Y., (2020). Early Transmission Dynamics in Wuhan, China, of Novel Corona virus-Infected Pneumonia. New England Journal of Medicine. 2020.

[10] MacIntyre, C.R., Costantino, V., \& Kunasekaran, M.P. (2019). Health system capacity in Sydney, Australia in the event of a biological attack with smallpox. PLOS One. 2019;14(6).

[11] MacIntyre, C.R. (2020). Global spread of COVID-19 and pandemic potential. Global Biosecurity, 2020; 1(3). Published: February 2020

[12] National Center for Immunization and Respiratory Diseases(NCIRD) (2020).COVID-19 Employer Information for Office Buildings. U.S Centers for Disease Control and Prevention $(C D C)$. Retrieved 9 July 2020.

[13] Nishiura, H., Kobayashi, T., Yang, Y., Hayashi, K., Miyama, T., \&Kinoshita, R. (2020). The Rate of Under ascertainment of Novel Corona virus (2019-nCoV) Infection: Estimation Using Japanese Passengers Data on Evacuation Flights. Multidisciplinary Digital Publishing Institute; 2020.

[14] Peak, C.M., Childs, L.M., Grad, Y.H.,\& Buckee, C.O. (2017). Comparing no pharmaceutical interventions for containing emerging epidemics. Proceedings of the National Academy of Sciences. 2017;114(15):4023-8.

[15] Scipioni, J. (2020).Why there will soon be tons of toilet paper, and what food may be scarce, according to supply chain experts. CNBC. Retrieved 19 March 2020.

[16] Smith, A.C., Thomas, E., Snoswell, C.L., Haydon, H., Mehrotra, A. Clemensen, J., \& Caffery, L.J. (2020). Telehealth for global emergencies: Implications for coronavirus disease 2019 (COVID-19)". Journal of Telemedicine and Telecare. 26 (5): 309-313. doi: $10.1177 / 1357633 \times 20916567$. PMC 7140977. PMID 32196391.

[17] Stadnytskyi, V., Bax, C.E., Bax. A., \&Anfinrud, P. (2020). The airborne lifetime of small speech droplets and their potential importance in SARS-CoV-2 transmission. Proceedings of the National Academy of Sciences of the United States of America. 117 (22): 11875-11877. doi: $10.1073 /$ pnas.2006874117. PMC 7275719. PMID 32404416

[18] U.S. Centers for Disease Control and Prevention(2020). Caring for Yourself at Home. Retrieved 23 March 2020.

[19] U.S. Centers for Disease Control and Prevention (2020). How COVID-19 Spreads. 2 April 2020. Archived from the original on 3 April 2020. Retrieved 3 April 2020.

[20] UNESCO (2020). Education: From disruption to recovery. UNESCO. 4 March 2020. Retrieved 28 March 2020.

[21] United Nations (2020). As famines of 'biblical proportion' loom, Security Council urged to 'act fast. UN News. 21 April 2020. Retrieved 10 July 2020

[22] Velavan, T.P., \&Meyer, C.G. (2020). "The COVID-19 epidemic". Tropical Medicine \& International Health. 25 (3): 278-280. doi: $10.1111 / \mathrm{tmi} .13383$. PMC 7169770. PMID 32052514.

[23] Wang, D., Hu, B., Hu, C., Zhu, F., Liu, X., \&Zhang, J., (2020). Clinical Characteristics of 138 Hospitalized Patients With 2019 Novel Coronavirus-Infected Pneumonia in Wuhan, China. JAMA. 2020.

[24] Watts, J., \& Kommenda, N. (2020). Coronavirus pandemic leading to huge drop in air pollution. The Guardian. ISSN 0261-3077. Retrieved 8 April 2020. 
[25] World Bank (2020). Updated estimates of the impact of COVID-19 on global poverty. World Bank. 8 June 2020.

[26] World Health Organization (2020).Statement on the second meeting of the International Health Regulations (2005) Emergency Committee regarding the outbreak of novel corona virus $(2019 \mathrm{nCoV})$. Archived from the original on 31 January 2020. Retrieved 30 January 2020.

[27] World Health Organization (2020). Naming the corona virus disease (COVID-19) and the virus that causes it. Archived from the original on 31 January 2020. Retrieved 30 January 2020.

[28] World Health Organization (2020). Novel Corona virus-China World Health Organization (WHO). Retrieved 9 April 2020.

[29] World Health Organization (2020). WHO Director-General's opening remarks at the media briefing on COVID-19-11 March 2020. Retrieved 11 March 2020.

[30] Xu, X., Chen, P., Wang, J., Feng, J., Zhou, H., \&Li, X. (2020). Evolution of the novel coronavirus from the ongoing Wuhan outbreak and modeling of its spike protein for risk of human transmission. Science. China Life Sciences. 2020:1-4.

[31] Zou, L., Ruan, F., Huang, M., Liang, L., Huang, H., Hong, Z. (2020). SARS-CoV-2 Viral Load in Upper Respiratory Specimens of Infected Patients. New England Journal of Medicine. 2020. 